\title{
Possibilidades da Clínica Gestáltica no Atendimento de Crianças Enlutadas
}

\section{Possibilities of the Gestalt Clinic in the Care of Bereaved Children}

\section{Posibilidades de la Clínica Gestaltáltica en el Cuidado de Duelo en la Infancia}

\author{
Daniela Pupo Barbosa Bianchi* \\ Pontifícia Universidade Católica de São Paulo - PUC-SP, São Paulo, São Paulo, Brasil
}

\section{Ida Kublikowski**}

Pontifícia Universidade Católica de São Paulo - PUC-SP, São Paulo, São Paulo, Brasil

\section{Patricia Barrachina Camps***}

Pontifícia Universidade Católica de São Paulo - PUC-SP, São Paulo, São Paulo, Brasil

\section{Maria Helena Pereira Franco****}

Pontifícia Universidade Católica de São Paulo - PUC-SP, São Paulo, São Paulo, Brasil

\begin{abstract}
RESUMO
O luto é compreendido como o processo psíquico de elaboração de uma perda que rompe com toda a constituição de mundo interno e segurança da criança, exigindo que novas formas de ajustamento sejam criadas. A presença de um outro-suporte é fundamental para que a criança possa percorrer seus ciclos de contato e alcançar a satisfação de suas necessidades no enfrentamento do luto. A Gestalt-terapia é uma abordagem fenomenológico-existencial, focada na construção dialógica, na qual a relação terapeuta-cliente ganha um eixo central. Em termos de prática clínica, o terapeuta se coloca em abertura à espera do outro-humano que o busca, na expectativa de que se revele, acolhendo os conteúdos, reconhecendo sua manifestação, em um processo de aceitação, confirmação e inclusão. Neste sentido, a intervenção terapêutica acompanha a expressão do brincar como linguagem para a criança comunicar, compreender e assimilar o vivido. O caminho escolhido para realização deste estudo foi a revisão bibliográfica de teóricos da Gestalt-terapia e estudos em luto na contemporaneidade, com enfoque nas bases relacionais destas teorias associadas a vinhetas de casos clínicos para ampliar a compreensão e possibilidades de intervenção com crianças enlutadas na clínica gestáltica.

Palavras-chave: luto infantil, gestalt-terapia, psicoterapia infantil.
\end{abstract}

\section{ABSTRACT}

Grief is understood as the psychic process of elaboration of a loss that breaks with the entire constitution of the inner world and the child's safety, 
requiring that new forms of adjustment be created. The presence of another support is fundamental for the child to be able to go through their cycles of contact and achieve the satisfaction of their needs in facing grief. Gestalt therapy is a phenomenological-existential approach, focused on dialogic construction, where the therapist-client relationship takes on a central axis. In terms of clinical practice, the therapist stands open waiting for the other human who seeks him, expecting to reveal himself, welcoming the contents, recognizing their manifestation, in a process of acceptance, confirmation and inclusion. In this sense, therapeutic intervention accompanies the expression of play as a language for the child to communicate, understand and assimilate the lived experience. The path chosen for this study was the bibliographic review of Gestalt therapy theorists and studies in mourning in contemporaneity, focusing on the relational bases of these theories associated with clinical case vignettes to broaden the understanding and possibilities of intervention with bereaved children in the clinic gestalt.

Keyword: child bereavement, gestalt-therapy, child psychotherapy.

\section{RESUMEN}

El duelo se entiende como el proceso psíquico de elaboración de una pérdida que rompe con toda la constitución del mundo interior y la seguridad del niño, requiriendo la creación de nuevas formas de ajuste. La presencia de otro apoyo es fundamental para que el niño pueda pasar por sus ciclos de contacto y alcanzar la satisfacción de sus necesidades al enfrentar el dolor. La terapia gestáltica es un enfoque fenomenológico-existencial, centrado en la construcción dialógica, donde la relación terapeuta-cliente adquiere un eje central. En términos de práctica clínica, el terapeuta permanece abierto esperando al otro ser humano que lo busca, esperando revelarse, acogiendo los contenidos, reconociendo su manifestación, en un proceso de aceptación, confirmación e inclusión. En este sentido, la intervención terapéutica acompaña la expresión del juego como lenguaje para que el niño se comunique, comprenda y asimile la experiencia vivida. El camino elegido para este estudio fue la revisión bibliográfica de los teóricos de la Terapia Gestalt y los estudios contemporáneos de duelo, centrándose en las bases relacionales de estas teorías asociadas con viñetas de casos clínicos para ampliar la comprensión y las posibilidades de intervención con niños en duelo en la clínica gestáltica.

Palabras clave: duelo infantil, terapia gestalt, psicoterapia infantil.

O pensar sobre a vida inclui o pensar sobre a morte, quem somos, quais nossas crenças e mitos sobre a finitude. Estas questões carregam consigo profundas reflexões acerca do sentido dado à vida e às relações.

Colin Parkes (1998), importante teórico dos estudos sobre o luto nos diz que "A dor do luto é tanto parte da vida quanto a alegria de viver; é talvez, o preço que pagamos pelo amor, pelo compromisso." (p. 22). O autor nos ensina que amar está implicado no enfrentamento cotidiano do risco de perder o ser amado.

O processo de desenvolvimento humano implica em formação e rompimento de vínculos com outros-significativos. Perdas são parte do existir humano, realidade ontológica e condição indissociável da existência. O luto é o processo psíquico de elaboração de uma perda. 
Parkes (1998) entende este processo como uma aprendizagem, no qual a pessoa passa por um percurso significativo de mudança de sua percepção de mundo a medida em que vai assimilando esta experiência, que rompe com toda a constituição de mundo interno e segurança, e exige que novas formas de ajustamento sejam criadas, para que o mundo interno possa ser reconstruído a partir de uma nova configuração.

Se para os adultos deparar-se com a vivência da morte de uma pessoa amada representa uma travessia de dor e sofrimento, como podemos pensar no enfrentamento da morte pela criança? No universo infantil de brincadeiras, pensamentos mágicos, contos de fadas e super-heróis existe espaço para a morte, como evento universal, inevitável e irreversível? A criança pode viver um processo de luto? Quando a criança descobre a morte? Quais os fatores relacionados a esta descoberta? A busca de respostas para estas perguntas encontra lugar ao refletirmos sobre as questões que cercam o processo de vivência de perdas e enfrentamento do luto na infância.

Torres (2012) aponta a importância da morte como um fator de organização tanto no que se refere ao desenvolvimento cognitivo, como na questão de constituição da subjetividade. Para a autora, a criança vivencia o processo de luto e responde a ele, porém esta resposta está relacionada, além de sua fase de desenvolvimento, com a qualidade e intensidade do vínculo afetivo estabelecido com a pessoa perdida. Muitas vezes, por manifestar reações diferentes das reações dos adultos, estas não são entendidas como uma resposta à perda.

A vivência da perda é mais dolorosa e exigente quando esta se refere a uma figura de apego significativa na história da criança. Além da perda de sua base de segurança, muitas vezes a criança não pode contar com um adulto disponível para acolher seu sofrimento e angústias, pois o sistema familiar também vive um enfrentamento doloroso. Para os adultos pode ser difícil lidar com o tema da morte visto que o confronta com sua própria finitude (Torres, 2012). Deste modo, muitas vezes a criança pode se beneficiar de uma intervenção terapêutica, que ocupa o lugar de outro-suporte amparando sua travessia.

A escassez de pesquisas e trabalhos sobre o luto da criança em Gestalt-terapia nos leva a pensar na relevância de refletir sobre o enfrentamento do tema a partir de um enfoque relacional, destacando a presença do outro que o acolha e atue como heterossuporte neste processo. Com isso, foi realizada revisão bibliográfica de obras importantes na Gestalt-terapia em diálogo com estudos contemporâneos sobre o processo de luto, destacando os realizados pelos estudiosos da Teoria do Apego, desenvolvida por John Bowlby (1979) e o Modelo do Processo Dual do Luto, proposto 
por Stroebe e Schut (1999, 2001), com objetivo de ampliar a compreensão e possibilidades de intervenção com crianças enlutadas na clínica gestáltica.

O Modelo do Processo Dual propõe que o enlutado oscila entre dois sentidos, um orientado para a perda e um orientado para a restauração, e em um processo saudável, transita entre eles de forma não linear e não simultânea. No sentido da perda, ocorre propriamente o trabalho de luto, expressão de pesar e sentimentos a ela relacionados, de forma a identificar e constituir recursos suportivos internos e externos. Por seu turno, no sentido de restauração, estão os movimentos relacionados a retomada da vida e retorno às atividades cotidianas, sendo identificados e constituídos, consequentemente, os recursos internos e externos. Para Franco (2010, p. 34) essa compreensão "Oferece uma estrutura analítica para entender como as pessoas se adaptam à perda de alguém significativo."

Este modelo traz importante luz sobre a compreensão do processo de luto, visto que possibilita o entendimento de que este processo não ocorre apenas quando se está no enfrentamento da dor, mas acontece também quando existe a necessidade de afastamento do sofrimento para retomada do cotidiano. Esta oscilação é fundamental para o processo de autorregulação organísmica e retomada da homeostase. Este modelo de compreensão dialoga com a visão de saúde da Gestalt-terapia que entende que a saúde está no movimento e ritmo entre as polaridades, e que o adoecimento acontece a partir de cristalizações e paralisações.

Cabe pensar no processo de luto da criança a partir destes dois movimentos, entendendo que cada criança tem um ritmo próprio e diferente do adulto para fazer este percurso, considerando as particularidades de seu processo de desenvolvimento cognitivo e afetivo.

A partir dos referenciais dialógicos da Gestalt-terapia, compreendemos que a subjetividade é construída a partir do encontro humano, que reconhece e confirma o outro-sujeito, permitindo que sua humanidade seja inaugurada a partir de uma relação de inclusão, presença e confirmação (Hycner, 1995). Tal como a Gestalt-terapia, a Teoria do Apego compreende o homem como ser em relação, e a partir destas bases que sustentam o encontro humano, reside a visão de processo terapêutico sustentada neste artigo. As contribuições da Teoria do Apego na compreensão de formação e rompimento de vínculos amplia a compreensão sobre o processo de enfrentamento de perdas significativas. Dialoga com a Gestalt-terapia, ambas destacando o fator relacional e a importância do terapeuta como outro-suporte, base de segurança que acolhe e testemunha a criança em seus enfrentamentos. 
A partir de um diálogo entre estas teorias, serão trazidos recortes de casos clínicos que destacam a importância da relação terapêutica e o encontro terapeuta-cliente através da linguagem dos símbolos e do brincar nos quais a criança se comunica e apreende o mundo, e como estes podem ser valiosos recursos na clínica do luto.

\section{Gestalt-terapia com crianças}

A Gestalt-terapia é uma abordagem psicoterapêutica compreendida a partir de um referencial fenomenológico-existencial, focada na construção dialógica, na qual a relação terapeuta-cliente ganha um eixo central.

Este olhar coloca terapeuta e cliente juntos para destacar a relação construída no "entre": espaço fronteiriço onde a experiência se dá, levando o indivíduo-organismo ao crescimento.

A experiência se dá na fronteira entre o organismo e seu ambiente, primordialmente a superfície da pele e os outros órgãos de resposta sensorial e motora. A experiência é função dessa fronteira, e psicologicamente o que é real são as configurações 'inteiras' desse funcionar, com a obtenção de algum significado e a conclusão de alguma ação. (Perls, Hefferline, \& Goodman, 1997, p. 41).

Para os autores iniciais da Gestalt-terapia, acima citados, a experiência será essencialmente contato, a partir do funcionamento da fronteira entre o organismo e seu ambiente, sendo que toda função humana é um interagir num campo organismo/ambiente (Perls et al., 1997).

Nessa perspectiva, tempo, lugar e relação iluminam o trabalho terapêutico uma vez que o foco reside no aqui-e-agora no qual duas pessoas se encontram em um campo relacional co-construído para viver a experiência do diálogo inter-humano.

Vale destacar que o dialógico se assenta na perspectiva buberiana do encontro humano. Conforme Hycner (1995) "O termo 'dialógico' não se refere ao 'discurso' como tal, mas ao fato de que a existência humana, em seu nível mais fundamental é inerentemente relacional." (p. 22). Cardoso (2013) lembra que para Buber todo viver verdadeiro é encontro que se dá na esfera do "entre", criando uma experiência de intimidade onde o outro se torna presença e totalidade para mim. A importância dada à construção relacional torna o encontro terapêutico uma experiência potencial de ressignificação de situações inacabadas nas quais a necessidade dominante, que aparece em forma de dor ou sofrimento, pode ser satisfeita em um continuum de crescimento. 
Perls et al. (1997) ligam o sofrimento à criatividade, pois segundo os autores a dor é um sinal que indicaria um perigo atual, de onde o organismo irá buscar de maneira consciente forças e recursos para dar uma resposta espontânea a essa ameaça. Eis que o criativo emerge para que o organismo-indivíduo possa ajustar-se às novas demandas.

Vale neste momento o ensinamento de Cardella (2017) que enfatiza o encontro inter-humano como permeado de possibilidades de cuidado:

A consciência de nossa precariedade é a dimensão criativa do ser humano: é dimensão dialógica. O homem criativo é precário, aberto ao outro. A autossuficiência é ilusão perversa, adoecimento profundo, fechamento do homem sobre si mesmo, esquecimento de sua abertura fundamental: prisão solitária, com muros e grades. O sofrimento é um apelo ao outro, carrega a esperança do encontro. (p. 36).

Em termos de prática clínica, o terapeuta se coloca em abertura à espera do outro-humano que o busca, na expectativa de que seu cliente se revele e, então, possa acolher seu conteúdo, reconhecer sua manifestação, em um processo de aceitação, confirmação e inclusão. Essa postura encoraja a pessoa a se expressar, permitindo que suas experiências possam encontrar uma boa forma.

Por inclusão entende-se a postura de se colocar no lugar da outra pessoa sem que o terapeuta perca sua própria experiência subjetiva, em um fluxo de ir-e-vir em direção ao outro e a si mesmo. Neste sentido, o outro-sujeito é suportado em sua singularidade e em seu crescimento através de uma vivência compartilhada e assimilada. Há um fluxo entre o Eu, o Tu e o Nós.

A posição de abertura e acolhimento por parte do psicoterapeuta, permite ao cliente apresentar-se de maneira espontânea e autêntica, pressupostos necessários para a compreensão de saúde em Gestaltterapia. Perls et al. (1997, p. 105) afirmam que "Os sentimentos infantis não são importantes como um passado que deve ser desfeito, mas como alguns dos poderes mais belos da vida adulta que precisam ser recuperados: espontaneidade, imaginação, exatidão da awareness e manipulação".

No atendimento a crianças, a postura de abertura e aceitação se mantém com o incremento da forma como a linguagem se dá no encontro terapêutico. É notório que a linguagem infantil inclui todo um universo lúdico, onde a criança representa por meio do brincar suas experiências na relação com o ambiente onde está imersa.

Dentro dessa compreensão, pensar no processo de luto para a criança e os recursos terapêuticos a ele inerentes, inclui um olhar à particularidade desse momento existencial, no qual o terapeuta 
precisará criar um ambiente acolhedor, seguro e lúdico a fim de que o cliente possa encontrar formas de expressar sua dor e viver seus ciclos de contato com o heterossuporte necessário.

A psicoterapia gestáltica com crianças mantém o pressuposto básico da vinculação terapeuta-cliente a fim de que haja um espaço primordialmente seguro, suportivo e acolhedor. Não obstante esse ponto, Fernandes (2016) afirma que a Gestalt-terapia investe no estreitamento do contato por meio do desenvolvimento das funções de contato, na ampliação da awareness e na valorização da experiência, sendo certo que a criança faz tudo isso enquanto brinca.

O brincar é compreendido tanto como linguagem, quanto como recurso no trabalho psicoterapêutico infantil. O brincar é entendido como recurso porque é na construção da brincadeira que a criança veicula seu mundo interno, sua leitura das experiências e das relações com o ambiente e as pessoas ao seu redor; e como linguagem em razão do brinquedo ser o símbolo onde a criança irá depositar os significados ainda não necessariamente apreendidos e assimilados de suas vivências e que são trazidas para a relação terapêutica na busca dessa compreensão e elaboração.

A criança está sempre em contato com o novo, curiosa pelo mundo que se revela em novidade e possibilidade. Experimenta, por vezes em idas e vindas, por tentativa e erro, relacionar-se com o objeto do seu interesse (Fernandes, 2016), em fluxo de criatividade onde constrói e se transforma pela assimilação da experiência-interação. Desses aprendizados a criança desenvolve mecanismos e ferramentas para lidar com os desafios da vida.

$E$ neste contexto de figuras que emergem com vigor, graça e encantamento no brincar, a interlocução com o que ocorre no mundo interno do sujeito-criança vai se revelando em um diálogo-ato onde, por meio da ação motora que é o próprio fazer criativo, problemasolução podem se configurar em uma dança de formas na presença de um outro significativo que é o terapeuta. Lizias (2010) caminha nessa compreensão:

No trabalho com crianças, é possível perceber como cada figura emerge de modo brilhante. . . . O terapeuta é convidado a mergulhar no mar de cada figura de contato que a criança lhe apresenta. . . . Com crianças, quase não há tempo para esse movimento de revolver o pensamento. É ali, na hora, que acompanhamos o fluxo de intencionalidade de cada movimento da criança e participamos de seu mundo lúdico de cores e formas, aproximando-se de suas intensidades delicadas a cada momento. (p. 68).

Assim, quando a criança alcança a possibilidade de se relacionar de maneira criativa e singular, começa a existir uma troca de pessoa a 
pessoa e a possibilidade de ampliar a qualidade da relação para além das experiências constitutivas (Poppa, 2018).

Entretanto, a criança ainda não tem autossuporte suficiente para enfrentar todas as demandas emocionais que a vida impõe. E nesse caminho, a presença de um outro-suporte é fundamental para que a criança possa percorrer seus ciclos de contato e alcançar a satisfação de suas necessidades.

Assim, o terapeuta pode ser esse outro singular a ofertar a sustentação na travessia de diversos sofrimentos, cultivando as potencialidades da criança em contínuo processo de ajustamentos criativos e ajudando o campo familiar a cuidar das demandas presentes.

\section{Possibilidades de intervenção com crianças enlutadas na clínica gestáltica}

Na clínica com crianças enlutadas não cabem generalizações sobre como deve sentir ou comportar-se uma criança ao viver um processo de luto. Cada criança irá elaborar sua perda a partir de sua singularidade, considerando seu repertório de recursos, desenvolvimento biográfico e campo vivencial.

Nesta clínica, é fundamental a compreensão de que todo o processo de elaboração do luto pela criança perpassa seu processo de desenvolvimento, um dos pontos que difere o processo de elaboração do luto da criança para o adulto. As crianças estão em plena fase de desenvolvimento cognitivo e afetivo, o que faz com que a elaboração e significação vá acontecendo ao logo deste desenvolvimento e perdure em etapas distintas de sua vida, a partir da constituição de novos recursos suportivos e de enfrentamento (Mazorra, 2005).

A sensibilidade do terapeuta reside em perceber os recursos de enfrentamento e necessidades de expressão de sentimentos de pesar a partir da unicidade de cada criança, sendo sensível aos movimentos que a criança faz, seja em direção à perda ou à restauração. Uma postura terapêutica atenta e continente possibilita que a criança tenha espaço de expressão nos dois sentidos, compreendendo que é a partir da oscilação entre estes sentidos que a criança vai ressignificando e destinando a perda.

Os settings terapêuticos utilizados nos casos em estudo são constituídos de diversos recursos lúdicos, tais como: caixas de areia contendo diferentes texturas de areia (sendo duas caixas retangulares com fundo azul e uma caixa redonda negra), brinquedos que representam pessoas, animais, construções, plantas e pedras, figuras mitológicas e simbólicas, bonecas, carros, barcos, aviões, cercas, material gráfico (tinta, lápis de cor e giz de cera), diferentes tipos de papel, sucatas, jogos, livros, brinquedos de armar e massa 
de modelar (plastilina, argila e biscuit). Esses recursos permitem que a criança se expresse livremente, através da escolha espontânea e não direcionada.

As sessões são realizadas de maneira não diretiva, onde o cliente sente-se livre para escolher o material que irá usar naquele encontro, a fim de melhor expressar seu mundo interno, com a linguagem própria que é o brincar criativo. Neste sentido, o fenômeno vai se revelando e o diálogo terapeuta-cliente vai se construindo em um todo unificado e inclusivo.

Por certo que nesse fazer dialógico do brincar terapêutico, o terapeuta aceita o conteúdo que se revela, como necessidade dominante que pede um fechamento de gestalt, confirmando os sentimentos ali revelados e exercendo a inclusão desse mundo interno e dessa demanda legítima contribuindo com a destinação do que fora apresentado através da linguagem lúdica.

Com relação à psicoterapia infantil, o terapeuta ocupa diversos lugares relacionais sempre a partir da oferta do outro-cliente com objetivo de construir o melhor campo vivencial para o trabalho. Dentre esses lugares, o profissional pode ser chamado ao lugar de observador do fenômeno, cuja função principal é o de confirmar a existência do conteúdo revelado. Assim também o terapeuta pode ser chamado a participar da construção do ato criativo, ocupando lugares de personagem no enredo de forma direcionada pela criança ou de forma livre, onde poderá apresentar suas intervenções na linguagem simbólica do brincar.

Vejamos um exemplo clínico, recorte de uma sessão terapêutica com a pequena Tina (nome fictício), com 8 anos de idade, que já estava em processo terapêutico há aproximadamente um ano. Tina traz em uma sessão o desejo de construir um cemitério na caixa de areia negra. Naquela semana ela e sua família haviam experimentado a perda de um tio-avô materno. Sua mãe ficou muito mobilizada tanto fisicamente, com a necessidade de ajudar a família nos cuidados hospitalares do tio, como também emocionalmente em razão dos sentimentos que a perda trouxe. Tina acompanha todos os movimentos familiares daquele episódio e resolve em sua sessão terapêutica construir um cemitério e executar alguns sepultamentos.

Logo que chega ao consultório antes de entrar na sala, Tina me diz que "Hoje vamos fazer um cemitério." Pergunto a ela o porquê disso e se havia morrido alguém em sua família. A criança então me conta que "O titio da mamãe morreu" e que "A mamãe chorou muito." Ainda me questiona: "Você sabe o que acontece quando a pessoa morre?" Enquanto estabelecemos um diálogo sobre a morte e o morrer, Tina começa a construir seu cemitério. Está bastante excitada com os acontecimentos e parece bem determinada no que deseja expressar. Pede que eu a ajude na escolha dos elementos, 
mas sempre dando a última palavra quanto às miniaturas que serão depositados na caixa de areia.

Entre 0 ato de construção do espaço cemitério, há 0 ato sepultamento de personagens. Importante narrar que Tina quer me contar o que acontece com as pessoas mortas. Fica evidente o desejo de partilhar o "novo conhecimento" que guarda um tanto de mistério e algo terrorífico. Segundo ela, "O corpo vai para debaixo da terra e é comido pelos vermes e o espírito vai para o corpo de um bebê bem pequenininho que nasce de novo na família." Eu, então, pergunto quem havia lhe contato sobre como é o morrer e ela me responde que havia sido seu pai.

Seguimos nessa construção de um campo terapêutico onde a morte é encenada diversas vezes. Tina escolhe alguns personagens que serão enterrados em um caixão. Nesse brincar criativo, ela inicia seu processo de destinação do significado da morte, através de vários sepultamentos realizados.

Durante a sessão, Tina pôde explicar ao outro-significativo em um diálogo-ato o destino do parente falecido. Neste processo, revelar ao outro é também processo de assimilação e integração em si desta verdade ontológica, onde o organismo-sujeito busca de maneira consciente forças para responder ao novo (Perls et al., 1997).

A sessão se circunscreve em fazer enterros de personagens que vão se revezando. Percebo que houve um desconforto em Tina acerca do destino do corpo - "ser comido por vermes" - razão pela qual o tema é trazido e reencenado no fazer que é o próprio ajustamento criativo. Tina constrói o cenário final do cemitério onde, além de corpos enterrados, temos a presença de arbustos, símbolo da vida e do renascer. Neste ponto, ela pôde também expressar que a decomposição do corpo gera alimento para nova vida, representada pelos arbustos colocados sobre o caixão enterrado. Assim, o processo "vida-morte-vida" foi revelado e significado pela criança e um lugar em que a morte pôde ser conquistada em seu psiquismo.

Como terapeuta, fui convidada a ocupar um lugar de testemunha da história, participando da construção do símbolo-ato, sendo o outrosuporte e a base de segurança para que o tema pudesse ser explorado, revisitado e destinado. O diálogo inter-humano foi fundamental para que a criança se sentisse segura em um espaço livre e continente, onde angústias existenciais puderam transitar em processo de elaboração (Hycner, 1995; Cardella, 2017). O vínculo terapêutico já estava bem constituído e, como terapeuta, percebo que ocupo um lugar de uma figura de segurança e cuidado.

A construção do brincar inclui a escolha do tema, dos brinquedos e dos gestos, havendo uma encenação das questões trazidas pela criança, no caso a morte, o enterrar, a decomposição do corpo e o destino da pessoa após o morrer. 
Dessa pequena vinheta clínica percebemos quanto o espaço terapêutico pôde ser o lugar para que a criança retornasse à vivência da morte a fim de dar lugar ao conteúdo psíquico ainda não plenamente assimilado.

Ficou nítido nesse movimento-brincadeira que a questão do destino do corpo após a morte era um assunto ainda não digerido pelo metabolismo mental infantil. Poder recriar a experiência do enterro em companhia de uma figura de apego, permitiu à Tina percorrer seu ciclo de contato, buscando uma forma harmoniosa para a vivência da perda e de seus conteúdos.

Sob o ponto de vista do Modelo do Processo Dual, o processo de luto de Tina estava orientado para a perda, uma vez que transitava pelos sentimentos a ela vinculados, bem como pela busca de recursos internos para lidar com o momento (Stroebe \& Schut, 1999, 2001).

Em outro exemplo por meio do recorte de processo terapêutico, Nina (nome fictício), de 9 anos, após uma vivência múltipla de perdas, constrói na caixa de areia retangular uma cena, na qual enterra no centro uma família, posicionando no entorno personagens do universo infantil. Cabe apontar que Nina está em processo terapêutico há cerca de dois meses, e que em sua primeira sessão, na qual apresentei a sala e os recursos disponíveis, contei sobre a possibilidade de utilizar a caixa de areia e as miniaturas, disponíveis nos armários da sala de atendimento.

Trata-se de um caso de violência e negligência infantil, no qual as circunstâncias da perda de seus pais não estão totalmente esclarecidas. Sabe-se, porém, que os principais cuidadores foram também seus agressores, criando uma espiral de sofrimento, ambivalência e insegurança. A morte dos pais levou a institucionalização da criança e de seus irmãos, acentuando ainda mais os lutos vivenciados pela criança, que além dos pais, perde toda a estrutura que lhe é familiar, necessitando desenvolver ajustamentos ao novo que lhe é apresentado.

Quando chega na sessão citada, Nina me pergunta "Posso brincar na areia hoje?" Respondo que sim e ela percorre as caixas para escolher a textura de areia que Ihe agrada mais. Embora estejamos em início de processo, percebo ela confortável com minha presença, o que indica que um vínculo seguro está sendo estabelecido. Se mostra afetuosa no contato comigo e se sente segura para solicitar minha ajuda quando necessário. Nina faz sua construção sozinha, silenciosa, na qual ocupo o lugar de testemunha, sendo para a criança o outrosuporte que possibilita a ela expressar seus sentimentos, através do uso das miniaturas e da caixa de areia. Cardella (2017) nos ensina que "Quando há presença de um outro o sofrimento pode ser comunicado e torna-se passagem, portanto experiência no tempo, movimento de vir a ser, esperança." (p. 144). 
Nina me conta que gosta e se identifica com a personagem "Moana". Elege então toda a família da personagem para representar a cena, depositando os elementos no centro da caixa deitados e colocando areia sobre eles, construindo um enterro simbólico da família. A colocação de areia sobre os personagens é realizada de maneira lenta e cuidadosa, de forma a cobrir todas as partes. A partir do ato livre e criativo do brincar, pôde expressar a cena dolorosa da perda da família.

Constrói então um entorno de personagens de histórias infantis e contos de fadas com o olhar direcionado para a frente da caixa, no eixo horizontal. Para tanto, busca nos armários aos poucos as miniaturas selecionadas e vai depositando uma a uma na caixa de areia. Na primeira imagem (figura 1), vemos a caixa finalizada.

O gesto espontâneo de Nina, expresso pelo movimento de encenar o ato de enterro pode ser entendido como sua necessidade de representar o enfrentamento da perda familiar, indicando que, a partir da compreensão do Modelo do Processo Dual, ela esteja transitando na orientação da perda, movimento necessário para significação e destinação de seus sentimentos.

Sua construção é livre, e entendo que minha participação no ato de expressão do brincar seja ocupar um lugar de testemunha, em um diálogo silencioso de presença e inclusão dos sentimentos legítimos, necessários para elaboração psíquica das perdas vividas.

Finaliza mantendo os personagens enterrados e após a finalização da sessão, quando Nina já foi embora, na desmontagem (figura 2), desenterro a família para registro fotográfico. A cena pode evocar tanto a questão da perda da unidade familiar, que embora precária, representava a única conhecida pela criança, como a impossibilidade presente de olhar para estas questões tão dolorosas, mantendo a representação familiar enterrada pela areia.

A partir da oferta de um setting terapêutico que proporcione um acolhimento seguro e continente, as dores e questionamentos sobre a morte podem começar a ter lugar, ainda que de forma gradativa, permitindo que a criança constitua recursos de enfrentamento e fortaleça seu autossuporte. Em uma relação de abertura e disponibilidade, o terapeuta atua como outro-suporte, acolhendo as expressões da criança, sendo guardião de suas dores e temores e respeitando seu tempo e ritmo de assimilação. 


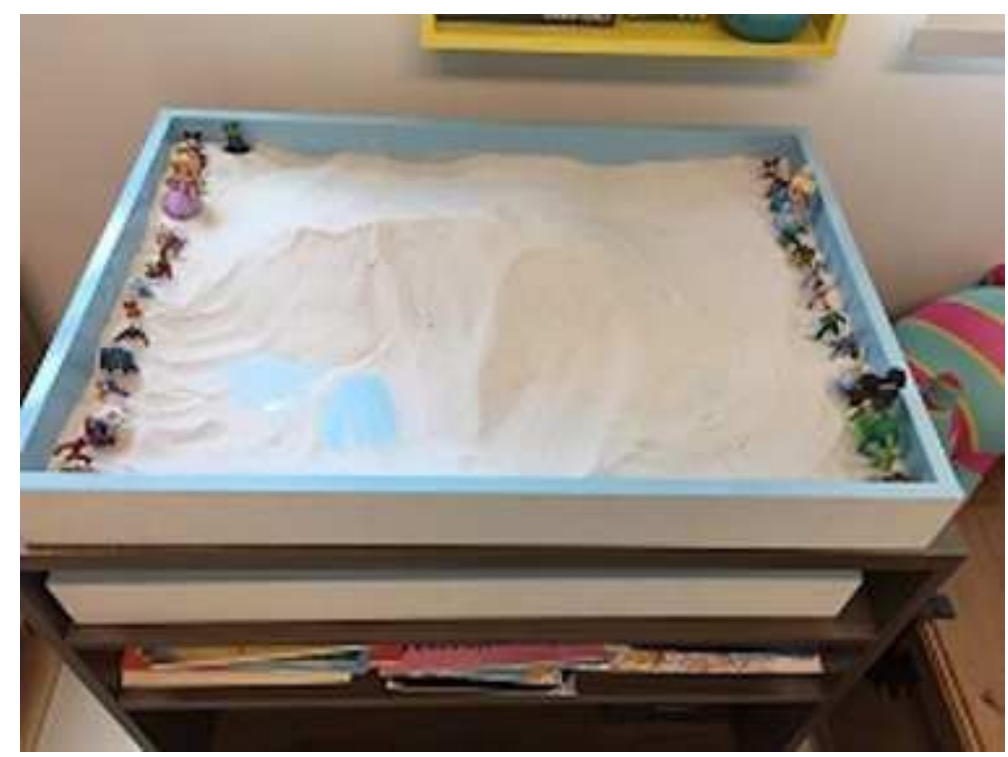

Figura 1: Família enterrada

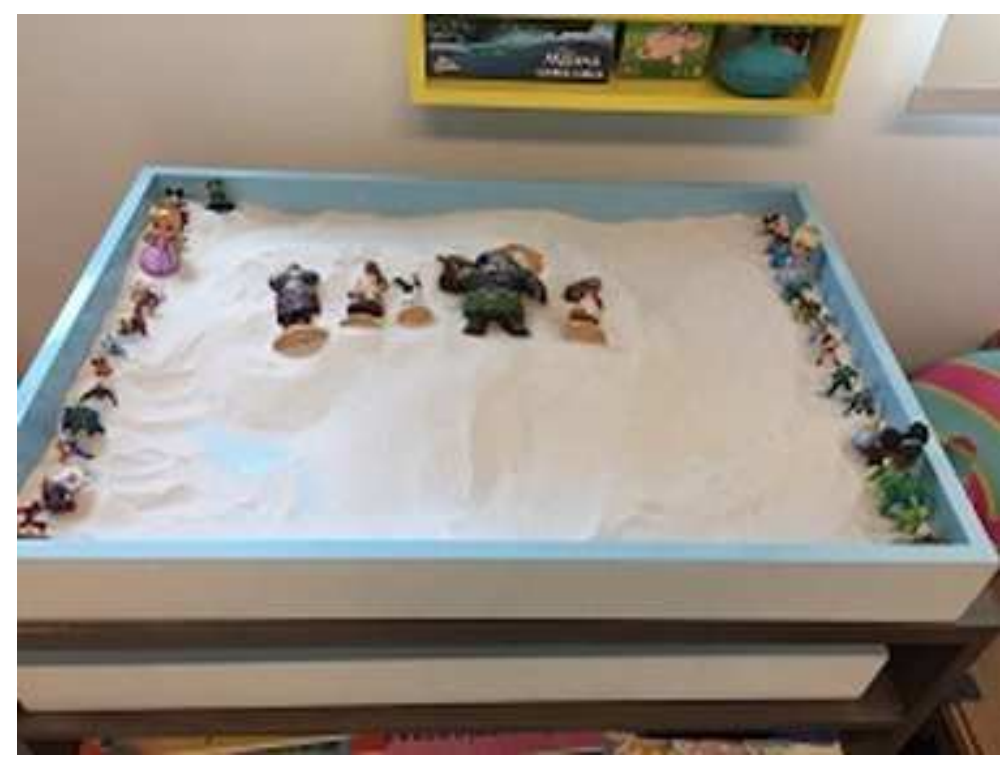

Figura 2: Família exposta

Estes recortes fazem pensar que a oferta de recursos lúdicos, que tragam possibilidades de expressão verbal e não verbal constituem valioso instrumento no cuidado com crianças enlutadas, pois esses recursos permitem que emoções acerca da perda e sentimentos por elas suscitados, sejam externalizados e possam ser gradativamente significados e destinados.

Ao terapeuta que acompanha a criança nesta vivência versa a necessidade de estar atento para testemunhar os movimentos necessários ao seu processo de elaboração, atuando de forma continente e suportiva para que a criança possa comunicar, nomear e identificar recursos a fim de atender suas necessidades e anseios. 
Neste sentido, a presença do terapeuta representa esse suporte humano necessário com o intuito de que a criança comunique seu sofrimento.

Esse campo relacional terapeuta-cliente oferta à criança entrar em contato com suas questões emocionais uma vez que encontra uma base de segurança para poder transitar tanto na dor perda, como também na restauração. As figuras podem então emergir de um fundo, com mais força e nitidez, permitindo que o diálogo interhumano contribua com a travessia do sofrimento. Assim, a criança organiza suas experiências em uma totalidade que envolve as funções perceptuais, movimento (ação motora) e interação (relação). Para Antony (2010) o Gestalt-terapeuta desenvolve um olhar atento à experiência do brincar, sem a intenção de interpretar o fenômeno que vê, mas focado em descrever e explorar o que é observado no ambiente terapêutico, entendendo que a criança dará o significado às vivências experimentadas. Deste modo, a experiência será a própria via da consciência para a criança.

\section{Considerações finais}

A clínica com pacientes enlutados é uma clínica de cuidado e delicadeza, visto que o encontro com a morte de pessoas significativas pode indicar o atravessamento de lugares habitados por sofrimentos e dores intensas e profundas. Assim também no âmbito do trabalho com crianças, que após perder uma pessoa amada precisa reconstruir sua percepção de mundo e relações, inaugurando uma nova forma de existência e significados.

Desta maneira, o encontro terapêutico, compreendido em Gestaltterapia como "Solo fértil a partir do qual o paciente pode enraizar-se, acontecer em sua singularidade, atualizar em suas potencialidades e destinar-se, ou seja, colocar-se em marcha e travessia" (Cardella, 2014 , p. 109), oferece a base de segurança necessária para que a criança encontre espaço para existir, em suas dores, angústias, dúvidas acerca da morte como também para se afastar deste processo e transitar em sentido a continuidade da vida.

O trânsito entre os polos "viver a dor da perda" e "restaurar o mundo presumido" vai possibilitando que a criança ressignifique a morte de uma pessoa amada, construindo para ela uma nova destinação na qual esta pessoa passa a habitar o seu mundo interno, representação mental e afetos. Desta forma, Kovacs (1992) nos diz que "O processo de luto está finalizado quando existe a presença da pessoa perdida internamente em paz, e há um espaço disponível para outras relações. A criança pode simbolizar esta ausência/presença em forma de jogos e brincadeiras." (p. 50). 
Esta simbolização é alcançada pela criança na relação terapêutica, quando o terapeuta em uma postura de abertura e sensibilidade entra no universo sagrado do brincar e compreende a linguagem e experiências da criança, nas quais são fundadas novas possibilidades de existir em processo de ajustamento criativo da novidade.

Como vimos nos recortes apresentados, por meio da representação de perdas reais ou simbólicas, o brincar oferta à criança a possibilidade de organizar esses conteúdos (Fernandes, 2016), para que possam ser gradativamente integrados em sua vida. Construir cenas onde emerjam como figuras as questões relacionadas com a morte, novas configurações de vida, novos papéis e identidades, podem abrir portas para que novos significados sejam construídos e a criança se coloque em travessia para esta nova vida que se apresenta.

A comunicação do vivido a partir do brincar acontece fundada nas bases dialógicas constituídas na relação terapêutica, confirmando e validando os sentimentos da criança em um movimento de inclusão e aceitação genuínas. Cardella (2017) enfatiza que "O sofrimento é um apelo ao outro, carrega a esperança do encontro." (p. 36).

Como apontou Lizias (2010), no trabalho com crianças a figura que emerge de forma brilhante, convida o terapeuta ao mergulho nesse mar de significados no aqui-e-agora da relação terapêutica, acompanhando o fluxo de intencionalidade dos movimentos lúdicos permeados de cores e formas.

É possível apontar, a partir dos recortes clínicos apresentados, que o recurso lúdico atuou como facilitador no processo de comunicação de sofrimento e angústias da criança em relação à morte e demais fatores inerentes a este processo. A oscilação entre as orientações de perda e restauração, conforme concebida no Modelo do Processo Dual do Luto, se expressa aqui no encenar e reencenar a cena, ressignificar e atribuir significado à morte, movimentos essenciais para o processo de elaboração do luto, bem como todos os gestos em direção ao novo e à construção do viver a partir da ausência do outro-significativo perdido.

Assim, nesse diálogo teórico encontramos pontos convergentes e outros que se somam em uma construção de compreensão e prática clínica para o processo de luto. Este artigo não pretende encerrar as discussões sobre o tema, mas abrir um espaço para que a interface seja iniciada e contribuições singulares possam ser colhidas no incremento na prática clínica com crianças em processo de luto dentro da perspectiva da Gestalt-terapia.

A Gestalt-terapia com seu entendimento de saúde a partir do fluxo entre as polaridades, ritmo necessário ao viver em contrapondo aos estados de cristalização, conversa com o Modelo do Processo Dual que aponta para o processo de luto como o ir-e-vir entre vivência da dor e restauração. Nesse encontro, o manejo reside em sustentar a 
experiência do cliente no ritmo apresentado durante sua vivência, sendo o terapeuta tanto o heterossuporte necessário, quanto a base de segurança no aprofundamento da travessia em qualquer dos polos desse fluir.

Além disso, a criatividade é apontada pela Gestalt-terapia como força motriz para a superação do sofrimento através dos diversos ajustamentos criativos realizados pelo enlutado a fim de lidar tanto com a perda, como com o processo de restauração. Para tanto, a experiência relacional terapêutica poderá fortalecer os recursos internos do cliente, criando um espaço para que este se expresse de maneira espontânea, deixando emergir a tão necessária criatividade. Os estilos relacionais e modelos internalizados de apego, constituídos a partir das experiências de cuidado e proteção, influenciam na forma como cada um vive a experiência da perda e constrói seu enfrentamento. $O$ que é comum a todas, com ressalva às particularidades de cada vivência, é a necessidade de restaurar a base segura que permite atravessar este momento intenso de sofrimento.

O terapeuta se constitui em base segura e porto seguro para seu cliente e o acompanha tanto em sua expressão de pesar, como em sua retomada do cotidiano. Oferta escuta atenta e amorosa, continente para a expressão dos sentimentos, muitas vezes ambíguos e contraditórios que podem emergir nesta vivência.

O gestalt-terapeuta, por meio de uma atitude dialógica (Hycner, 1995; Cardoso, 2013; Cardella, 2017), faz-se presente para que a criança comunique seus sentimentos, atuando como o heterossuporte necessário no atravessamento deste sofrimento. Esta base relacional possibilita à criança companhia para percorrer seus ciclos de contato (Poppa, 2018), realizando ajustamentos criativos funcionais e alcançando formas harmoniosas no existir.

\section{Referências}

Antony, S. (2010). Um caminho terapêutico na clínica gestáltica com crianças. In S. Antony, (Ed.), A clínica gestáltica com crianças: caminhos de crescimento (pp. 79-108). São Paulo, SP: Summus Editorial.

Bowlby, J. (1979). Formação e rompimento dos laços afetivos. São Paulo, SP: Martins Fontes.

Cardella, B. H. P. (2014). Ajustamento criativo e hierarquia de valores ou necessidades. In L. M. Frazão \& K. O. Fukumtsu (Eds.), Gestalt-terapia: conceitos fundamentais (pp. 109-134). São Paulo, SP: Summus Editorial.

Cardella, B. H. P. (2017). De volta para casa: ética e poética na clínica gestáltica contemporânea. São Paulo, SP: Gráfica Foca. 
Cardoso, C. L. (2013). A face existencial da Gestalt-terapia. In L. M. Frazão \& K. O. Fukumitsu (Eds.), Gestalt-terapia: fundamentos epistemológicos e influências filosóficas (pp. 59-75). São Paulo, SP: Summus Editorial.

Fernandes, M. B. (2016). Psicoterapia com crianças. In L. M. Frazão \& K. O. Fukumitsu (Eds.), Modalidade de intervenção clínica em Gestalt-terapia (pp. 56-82). São Paulo, SP: Summus Editorial.

Franco, M.H. (2010) Por que estudar o luto na atualidade? In Franco, M. H. (Org.), Formação e rompimento de vínculos. O dilema das perdas na atualidade (pp. 17-42). São Paulo, SP: Summus Editorial.

Hycner, R. (1995). De pessoa a pessoa: psicoterapia dialógica. São Paulo, SP: Summus Editorial.

Kovács, M. J. (1992). Morte e desenvolvimento humano. São Paulo, SP: Casa do Psicólogo.

Lizias, S. (2010). Epistemologia gestáltica e a prática clínica com crianças. In S. Antony (Ed.), A clínica gestáltica com crianças: caminhos de crescimento (pp. 47-78). São Paulo, SP: Summus Editorial.

Mazorra, L. (2005). O luto na infância. In L. Mazorra \& V. Tinoco (Eds.), Luto na Infância Intervenções psicológicas em diferentes contextos (pp. 111-126). São Paulo, SP: Livro Pleno.

Parkes, C. M. (1998). Luto: Estudos sobre a perda na vida adulta. São Paulo, SP: Summus Editorial.

Perls, F., Hefferline, R., \& Goodman, P. (1997). Gestalt-terapia. São Paulo, SP: Summus Editorial.

Poppa, C. C. (2018). O suporte para o contato: Gestalt e infância. São Paulo, SP: Summus Editorial.

Schut, H.; Stroebe, M. S., \& Stroebe, W. (2001). The efficacy of bereavement interventions: determining who benefits. In $M$. S. Stroebe, R. O. Hansson, W. Stroebe \& H. Schut, (Eds.), Handbook of bereavement research: consequences, coping and care (pp. 705-737). Washington: American Psychological Association.

Stroebe, M., \& Schut, H. (1999). The dual process model of coping with bereavement: rationale and description. Death Stud., 23(3), 197-224. doi: 10.1080/074811899201046

Torres, W. (2012). A criança diante da morte. São Paulo, SP: Casa do Psicólogo.

\section{Endereço para correspondência}

\section{Daniela Pupo Barbosa Bianchi}

Rua Trajano Reis, 155, apto 92B, CEP 05541-030, São Paulo - SP, Brasil

Endereço eletrônico: daniela.pupo@sedes.org.br 
Daniela Pupo Barbosa Bianchi, Ida Kublikowski, Patricia Barrachina Camps, Maria Helena Pereira Franco

\section{Ida Kublikowski}

Rua Ministro Godoy 969, $4^{\circ}$ andar, sl 4E-05, Perdizes, CEP 05015-901, São Paulo SP, Brasil

Endereço eletrônico: idakublikowski@pucsp.br

\section{Patricia Barrachina Camps}

Rua Cassiano Ricardo, 160, casa 6, Jardim Cordeiro, CEP 04640-020, São Paulo SP, Brasil

Endereço eletrônico: patriciabcamps@gmail.com

\section{Maria Helena Pereira Franco}

Alameda Campinas, 1493 apto 102, CEP 01404-002, São Paulo - SP, Brasil

Endereço eletrônico: mhfranco@pucsp.br

Recebido em: 16/09/2019

Reformulado em: 20/01/2020

Aceito em: 25/01/2020

\section{Notas}

* Psicóloga, doutoranda em Psicologia Clínica pela PUC/SP, gestalt-terapeuta pelo Instituto Gestalt de São Paulo, professora do IGSP, Sedes Sapientiae.

** Doutora em Psicologia Clínica pela Pontifícia Universidade Católica de São Paulo. Professora Associada, Programa de Estudos Pós-Graduados em Psicologia Clínica da PUC-SP.

*** Psicóloga, mestranda em Psicologia Clínica pela PUC/SP, Especialista em luto pelo Instituto Quatro Estações, Gestalt-terapeuta pelo Instituto Gestalt de São Paulo.

**** Professora titular da PUC-SP, pós-graduação em Psicologia Clínica.

Este artigo de revista Estudos e Pesquisas em Psicologia é licenciado sob uma Licença Creative Commons Atribuição-Não Comercial 3.0 Não Adaptada. 